\title{
Transition metal ions at the crossroads of mucosal immunity and microbial pathogenesis
}

\author{
Vladimir E. Diaz-Ochoa ${ }^{1,2}$, Stefan Jellbauer ${ }^{1,2}$, Suzi Klaus ${ }^{1,2}$ and Manuela Raffatellu ${ }^{1,2 *}$ \\ ${ }^{1}$ Department of Microbiology and Molecular Genetics, University of California, Irvine, Irvine, CA, USA \\ 2 Institute for Immunology, University of California, Irvine, Irvine, CA, USA
}

\author{
Edited by: \\ Mathieu F. Cellier, Institut National \\ de la Recherche Scientifique, \\ Canada \\ Reviewed by: \\ Simon C. Andrews, University of \\ Reading, UK \\ Guenter Weiss, Medical University \\ of Innsbruck, Austria \\ François Canonne-Hergaux, Institut \\ National de la Santé et de la \\ Recherche Médicale, France \\ *Correspondence: \\ Manuela Raffatellu, Department of \\ Microbiology and Molecular \\ Genetics, University of California, \\ Irvine, B251 Medical Sciences, \\ Irvine, CA 92697-4025, USA \\ e-mail: manuelar@uci.edu
}

Transition metal ions are essential micronutrients for all living organisms. In mammals, these ions are often protein-bound and sequestered within cells, limiting their availability to microbes. Moreover, in response to infection, mammalian hosts further reduce the availability of metal nutrients by activating epithelial cells and recruiting neutrophils, both of which release metal-binding proteins with antimicrobial function. Microorganisms, in turn, have evolved sophisticated systems to overcome these limitations and acquire the metal ions essential for their growth. Here we review some of the mechanisms employed by the host and by pathogenic microorganisms to compete for transition metal ions, with a discussion of how evading "nutritional immunity" benefits pathogens. Furthermore, we provide new insights on the mechanisms of host-microbe competition for metal ions in the mucosa, particularly in the inflamed gut.

Keywords: infection, nutritional immunity, iron, zinc, manganese, lipocalin-2, calprotectin, S100 proteins

\section{INTRODUCTION}

Transition metal ions are involved in many biological processes crucial for sustaining life. These metals can serve as cofactors in proteins, enabling their biological function, regulating their activity, and/or stabilizing their structure (Aisen et al., 2001; Andreini et al., 2008; Waldron et al., 2009). This mini-review focuses on three metal ions targeted by host sequestration strategies and the means by which microbes acquire them; namely, iron, zinc, and manganese.

Among transition metal ions, iron is the most abundant in the human body. Of the $3-5 \mathrm{~g}$ of iron in adults, $65-75 \%$ is located within erythrocytes bound to heme, the tetrapyrrole cofactor of hemoglobin, and utilized for oxygen transport (Andrews, 2000). Iron is also critical for other cellular processes in mammals, such as nucleic acid and protein synthesis, electron transport, and cellular respiration (Griffiths, 1999; Lieu et al., 2001). Most of the iron in the body is intracellular, and extracellular iron is associated with high-affinity iron binding proteins, namely transferrin and lactoferrin, so iron that microorganisms need for survival is severely restricted. Much like eukaryotic cells, microorganisms also utilize iron in DNA synthesis, electron transport, oxygen binding, and superoxide metabolism (Griffiths, 1999). Outside the body, the bioavailability of iron is generally limited due to the low solubility of ferric iron $\left(\mathrm{Fe}^{3+}\right)$ at physiological $\mathrm{pH}$ (7.4), likely facilitating microbial adaptation to low iron conditions (Raymond et al., 2005). In light of this, microbes that possess multiple iron uptake mechanisms, or those that can utilize alternative metal ions like zinc and manganese, are able to thrive when usable iron is scarce.
Zinc is an essential metal nutrient with an estimated dietary requirement in humans of $15 \mathrm{mg}$ per day (Tapiero and Tew, 2003; King, 2011). Approximately 95\% of zinc in humans is intracellular, where it serves structural and functional roles for a large number of macromolecules and enzymes (Tapiero and Tew, 2003; King, 2011). For prokaryotes, it is estimated that $5-6 \%$ of their proteome may consist of zinc binding proteins, which emphasizes the need for mechanisms of zinc acquisition in these cells (Andreini et al., 2006). In contrast to iron and zinc, only trace concentrations of manganese are found in human serum $(<10 \mathrm{nM})$ and tissue $(<4 \mu \mathrm{M})$ (Keen et al., 2000 ), which is likely to pose significant challenges for microorganisms that have adapted to thrive on earth's biosphere where manganese is widely available (Morgan, 2000). Only a handful of strictly manganese-dependent enzymes are known in both eukaryotes and prokaryotes because manganese in metalloenzymes appears to be readily interchangeable with other divalent cations (Andreini et al., 2008). Manganese in microbes is largely known for its role as a cofactor for some free radical detoxifying enzymes, but it also plays a key role in central carbon metabolism (Kehres and Maguire, 2003).

Transition metal ions are important biological catalysts because they can undergo changes in oxidation states involving one electron. To limit the unspecific reactive potential of transition metals, their availability in vertebrate hosts needs to be tightly regulated at all times and especially limited during infection, a process termed nutritional immunity (the sequestration of nutrients from pathogens). Host mechanisms of nutritional immunity are varied and include: the induction of hepcidin, a master hormone regulator that controls the levels of iron in the body 
(Drakesmith and Prentice, 2012); the expression of the Natural Resistance-Associated Macrophage Protein 1 (NRAMP1), an ion transporter that pumps iron and manganese out of pathogencontaining phagosomes (Jabado et al., 2000; Forbes, 2003; Cellier et al., 2007); and the expression of antimicrobial proteins that sequester metal ions at sites of infection (Aujla et al., 2008; Corbin et al., 2008; Raffatellu et al., 2009; Hood et al., 2012; Liu et al., 2012). Whereas all of these strategies aid the host in limiting the replication of infecting microbes, some microorganisms have evolved or acquired mechanisms of metal uptake that circumvent the nutritional immune response. Here we review some of the mechanisms that the mammalian host utilizes to sequester metal ions in response to infection, we describe how microbes can evade this nutritional immunity (with a focus on mucosal sites), and we discuss how circumventing this host defense benefits pathogens. Although transition metal toxicity and active intoxication are also established strategies in antimicrobial host responses, we will set our focus on the starvation of essential metal nutrients.

\section{MICROBIAL MECHANISMS OF ACQUIRING IRON}

Iron is required by numerous microbial species because it serves as a cofactor for important cellular processes including DNA replication, central metabolism and respiration. Microbes have thus evolved or acquired a variety of specialized iron uptake systems to overcome iron limitation. These systems are generally categorized as unbound iron, siderophore, or heme acquisition systems. Bacteria can uptake unbound iron using ferrous iron $\left(\mathrm{Fe}^{2+}\right)$ transport systems like Feo proteins, mechanisms that appear to be important mainly during low oxygen conditions, when ferrous iron remains more stable and predominate over ferric iron (Andrews et al., 2003). Such systems likely play a negligible role in bacterial iron acquisition under inflammatory conditions, where unbound iron is rarely found.

Under iron-limiting conditions, many pathogenic bacteria and some fungi synthesize and secrete siderophores; small, highaffinity iron-chelating compounds (Neilands, 1995). Siderophore effectiveness resides in their ability to bind ferric iron $\left(\mathrm{Fe}^{3+}\right)$ with an affinity that can exceed that of host $\mathrm{Fe}^{3+}$-binding proteins like transferrin or lactoferrin (Griffiths, 1999), enabling siderophores to "steal" iron from these host proteins. Microbial uptake of $\mathrm{Fe}^{3+}$ from siderophore- $\mathrm{Fe}^{3+}$ complexes is achieved by either the reduction of iron from the siderophore at the extracellular surface or by the internalization of the complex (Miethke and Marahiel, 2007). Filamentous fungi are capable of iron uptake by both routes (Philpott, 2006). Though the mechanisms of extracellular reduction by bacteria are not well-understood, the internalization of siderophore- $\mathrm{Fe}^{3+}$ complexes is well-studied (Crosa and Walsh, 2002; Krewulak and Vogel, 2008; Braun and Hantke, 2011). In Gram-negative bacteria, several outer-membrane receptors that transport siderophore- $\mathrm{Fe}^{3+}$ complexes have been identified; examples include the FepA receptor for enterobactin, and the FhuA receptor for ferrichrome (Chakraborty et al., 2007; Braun, 2009). The energy required by these receptors for the transport of the substrate originates from the proton motive force of the inner membrane and is transduced through the TonB protein complex (Braun and Braun, 2002; Moeck and Coulton, 2002; Postle and Kadner, 2003). Once in the periplasm, substrate-binding proteins (SBPs) shuttle the siderophore- $\mathrm{Fe}^{3+}$ complex to the corresponding ATP-binding cassette (ABC) transporter, which then translocates the complex into the cytoplasm (Biemans-Oldehinkel et al., 2006). ABC transporters in the cytoplasmic membrane of Gram-positive bacteria are also involved in the uptake of siderophore-Fe ${ }^{3+}$ complexes. Unlike Gram-negative bacteria, their cognate SBPs are responsible for initial binding of the complex and are tethered to the cytoplasmic membrane (Sutcliffe and Russell, 1995; Biemans-Oldehinkel et al., 2006). Once in the cytoplasm, iron can be liberated from siderophores through reduction of $\mathrm{Fe}^{3+}$ to $\mathrm{Fe}^{2+}$ or by enzymatic degradation of the siderophore (Miethke and Marahiel, 2007). Among bacteria, siderophore-based iron acquisition systems are widespread.

One of the most studied siderophores is enterobactin, also called enterochelin, which is synthesized by commensal and pathogenic Enterobacteriaceae including Escherichia coli, Klebsiella pneumoniae, and Salmonella spp (O'Brien and Gibson, 1970; Pollack and Neilands, 1970; Rogers et al., 1977; Perry and San Clemente, 1979; Lawlor and Payne, 1984). Enterobactin has high affinity for iron $\left(K_{a}=10^{51} \mathrm{M}^{-1}\right)$, which is higher than the affinity of host proteins like transferrin $\left(K_{a}=10^{20} \mathrm{M}^{-1}\right)$ (Aisen et al., 1978; Carrano and Raymond, 1979). Therefore, bacteria that synthesize enterobactin can efficiently scavenge iron from the host; however, the host innate immune response has evolved a mechanism to counteract enterobactin-mediated iron acquisition (discussed in detail below) (Fischbach et al., 2006). Although siderophores are generally secreted into the host extracellular environment, some siderophores aid iron acquisition by pathogens with a predominantly intracellular lifestyle. Mycobacterium tuberculosis (Mtb), for example, expresses siderophores known as mycobactins that diffuse out of Mtb-containing phagosomes, chelate iron from cytoplasmic stores, and re-enter the phagosome via lipid droplets (Luo et al., 2005).

In addition to siderophores, microbial pathogens can utilize different uptake systems to obtain iron from a variety of sources, which allow them to inhabit diverse niches and to respond to host mechanisms of iron sequestration. In the case of Candida albicans, uptake of unbound iron via the high-affinity iron permease FTR 1 is critical for establishing systemic infection in mice (Ramanan and Wang, 2000). In contrast, uptake of iron-bound siderophores is necessary for C. albicans colonization of epithelial layers but not for the development of a bloodborne infection (Heymann et al., 2002). Because C. albicans lacks the genes for the biosynthesis of siderophores (Haas, 2003), it depends on other microorganisms for the production of siderophores. Therefore, $C$. albicans uptake of iron via siderophores is likely restricted to sites where siderophore-producing microorganisms are found (e.g., mucosal surfaces in the gut). Another source of iron for microbes is the biggest pool of iron in the human body: iron from heme and heme-binding proteins.

Similar to the uptake of siderophore-bound iron, the first step in bacterial heme transport involves the binding of heme or hemoglobin to a surface receptor. In Gram-negative bacteria, TonB-dependent receptors are involved in the transport of heme into the periplasm, where heme-specific SBPs bind the molecule (Braun and Hantke, 2011). For hemoglobin, both 
Gram-negative and Gram-positive bacteria extract the heme group prior to transfer to an SBP. Heme-specific ABC transporters then translocate heme into the cytoplasm, where iron is released by heme-degrading enzymes (Braun and Hantke, 2011; Nobles and Maresso, 2011). Heme oxygenases catalyze the oxidative cleavage of heme with an electron donor to liberate iron (Nobles and Maresso, 2011). Subsequent catabolism of the heme is required to reduce the toxicity associated with the heme porphyrin (Nobles and Maresso, 2011).

\section{HOST MECHANISMS OF SEOUESTERING IRON}

Iron is essential for the replication of many pathogenic organisms, so it is not surprising that the host has evolved sophisticated strategies to limit the availability of iron to pathogens. Conversely, both iron supplementation and diseases characterized by iron overload, such as hemochromatosis, increase the host's susceptibility to infection (reviewed in Griffiths, 1999). In humans, the levels of unbound iron are low; most iron is bound by heme in the context of hemoglobin. Moreover, free heme can be captured by hemopexin and free hemoglobin by haptoglobin. Other proteins, like transferrin in serum, or lactoferrin in neutrophils and human secretions, bind strongly to ferric iron. In most cells, ferritin is responsible for storing iron for normal cellular use, but in specialized cells, i.e., hepatocytes and macrophages, ferritin is used for long-term iron storage and sequestration during iron overload, respectively (Andrews, 2000). Additionally, macrophages increase iron uptake and ferritin synthesis when converting to their inflammatory phenotype, suggesting that ferritin-based sequestration may be a key mechanism for intracellular iron withholding during infection (Birgegård and Caro, 2009).

An additional mechanism of regulating iron metabolism is mediated by the hormone hepcidin, which controls hostprotective responses by integrating signals from iron status and threat of infection. Initially identified as an antimicrobial peptide (Krause et al., 2000), hepcidin is considered to be the master hormonal regulator of iron metabolism, controlling both the overall level of iron and its localization (Nicolas et al., 2001; Park et al., 2001; Nicolas, 2002; Nemeth et al., 2003). Upon microbial infection, the upregulation of hepcidin, concomitant with a reduction of serum transferrin saturation, causes an overall decrease in iron levels (Nemeth et al., 2003; Armitage et al., 2011). Hepcidin upregulation is partially mediated through expression of pro-inflammatory cytokines like interleukin (IL-) 6, which stimulates the production of hepcidin in the liver (Nemeth et al., 2003, 2004a; Rodriguez et al., 2013). Hepcidin then inhibits both cellular iron efflux and duodenal iron absorption by binding to and inducing the degradation of the cellular iron transporter ferroportin 1, which exports iron into the plasma from cells that store or transport iron, including hepatocytes, macrophages, and absorptive enterocytes (Nemeth et al., 2004b; Ross et al., 2012). Subcutaneous infection with either Gram-negative or Gram-positive bacteria has been shown to induce hepcidin synthesis by neutrophils and macrophages, suggesting that local production of hepcidin may limit iron availability at sites of infection (Peyssonnaux et al., 2006). Overall, the induction of hepcidin upon infection results in hypoferremia and anemia of inflammation, which represent important host defense strategies to limit the availability of iron to pathogens.

One of the most studied host transporters in the context of bacterial pathogenesis is NRAMP1,- - a proton-dependent transporter of divalent metal ions expressed by professional phagocytes, such as macrophages and neutrophils (Cellier et al., 2007). This transporter is localized in the phagosomal membrane and exports $\mathrm{Fe}^{2+}$ and $\mathrm{Mn}^{2+}$ out of the phagosomal compartment, presumably to reduce access to these metals of pathogens residing within the phagosome (Cellier et al., 2007). While this export function occurs during infection, NRAMP1 is also known to contribute to hemoglobin iron recycling by reticuloendothelial macrophages that phagocytose senescent erythrocytes (Cellier et al., 2007; Soe-Lin et al., 2009). In addition to its phagosome metal-withholding function, expression of a functional NRAMP1 also restricts microbial growth by enhancing macrophage production of the antimicrobial effector molecule nitric oxide (NO) through sustained transcription of inducible nitric oxide synthase (iNOS) (Fritsche et al., 2003). Although the mechanism for iNOS induction is not fully understood, both STAT-1-mediated expression of the transcription factor IRF-1, as well as suppressed production of the inhibitory cytokine IL-10, contribute to NRAMP1-dependent prolonged activation of iNOS transcription (Fritsche et al., 2003, 2008). Similarly, another recent study using macrophage cell lines suggests that NRAMP1-mediated stimulation of the expression of lipocalin-2, an antimicrobial peptide that binds iron-loaded bacterial siderophores including enterobactin, is a novel mechanism by which NRAMP1 confers resistance to infection with the intracellular pathogen Salmonella enterica serovar Typhimurium (S. Typhimurium) (Fritsche et al., 2012). The importance of NRAMP1 in the host response to infection is further underlined by many studies showing that mice with a functional Nramp1 (Slc11a1) allele are more resistant to infection with a variety of intracellular pathogens including Mycobacterium bovis BCG, Leishmania donovanii, and S. Typhimurium (Forbes and Gros, 2001; Cellier et al., 2007).

Host mechanisms discussed thus far effectively reduce available iron, but they are not sufficient to completely prohibit bacterial iron acquisition during an infection. As discussed above, pathogenic bacteria can deploy an efficient weapon in the battle for iron: siderophores. However, as mammals have evolved for millions of years together with siderophore-producing bacteria, it is not surprising that we have evolved an anti-siderophore mechanism: secretion of lipocalin-2 (also known as siderocalin, neutrophil gelatinase-associated lipocalin, uterocalin, or 24p3) (Goetz et al., 2002; Flo et al., 2004; Correnti and Strong, 2012). Lipocalin-2 is one of the most abundant antimicrobial proteins released by epithelial cells and neutrophils during infections in the gut and respiratory mucosa with pathogens like S. Typhimurium and K. pneumoniae, respectively (Aujla et al., 2008; Bachman et al., 2009; Raffatellu et al., 2009). Lipocalin-2 sequesters a subset of catecholate siderophores, including enterobactin, thereby limiting bacterial access to iron (Goetz et al., 2002; Flo et al., 2004; Berger et al., 2006). In a sepsis model, lipocalin-2 induction is dependent on Toll-like receptor 4 signaling (Flo et al., 2004; Srinivasan et al., 2012). It is also known that lung and intestinal 
epithelial cells express and secrete lipocalin-2 in response to signaling by pro-inflammatory cytokines released by $\mathrm{T}$ helper 17 (Th17) cells, like interleukin IL-17 and IL-22 (Aujla et al., 2008; Raffatellu et al., 2009).

In addition to lipocalin-2, IL-17 and IL-22 also stimulate epithelial secretion of neutrophil chemoattractants, known as CXC chemokines, which mediate the recruitment of neutrophils to the mucosa (Awane et al., 1999; Andoh et al., 2005; Kao et al., 2005; McAllister et al., 2005; Aujla et al., 2008; Raffatellu et al., 2009). Neutrophils play a key role in nutritional immunity because they constitute the largest proportion of circulating white blood cells in humans, quickly mobilize to sites of infection, and express high levels of antimicrobial proteins that sequester metal ions, including lipocalin-2, lactoferrin, and, as detailed below, calprotectin (Masson et al., 1969; Steinbakk et al., 1990; Goetz et al., 2002). Thus, the coordinated expression and release of metalbinding antimicrobial proteins by epithelial cells and neutrophils during infection promotes host sequestration of essential metal nutrients.

In this tug of war for iron, pathogens have evolved mechanisms to counteract the sequestration of siderophores. To circumvent this arm of nutritional immunity, pathogens including Salmonella species, Klebsiella species and uropathogenic E. coli (UPEC) species synthesize salmochelin, a C-glucosylated derivative of enterobactin (Hantke et al., 2003; Bachman et al., 2011), which lipocalin-2 cannot bind, thus enabling iron uptake in these species and enhancing their colonization of host tissues (Fischbach et al., 2006; Crouch et al., 2008; Raffatellu et al., 2009; Bachman et al., 2011). Evasion of lipocalin-2-mediated iron sequestration is thus regarded as a virulence mechanism. However, work in our laboratory has recently shown that a probiotic strain of the Enterobacteriaceae family (E. coli Nissle 1917) also evades iron sequestration by lipocalin-2 in the inflamed gut via secretion of siderophores including salmochelin (Deriu et al., 2013). In this case, iron acquisition and evasion of lipocalin-2 is beneficial to the host, because E. coli Nissle 1917 reduces $S$. Typhimurium intestinal colonization by outcompeting it for iron acquisition (Deriu et al., 2013). Therefore, evasion of lipocalin-2 by the secretion of modified siderophores can confer a fitness advantage to probiotic strains like E. coli Nissle 1917 and enhance the host response against bacterial pathogens by further sequestering iron.

\section{MICROBIAL MECHANISMS OF ACQUIRING ZINC AND MANGANESE}

While the role of iron in cellular processes is well-characterized, increasing evidence suggests that other transition metal ions such as zinc and manganese also play a crucial role in microbial physiology (Keen et al., 2000; Hantke, 2005). For example, in order to circumvent host-mediated iron sequestration, Borrelia burgdorferi lacks most genes that code for iron-binding proteins, and, for the few metalloproteins it does express, B. burgdorferi uses manganese instead of iron (Posey and Gherardini, 2000). In many bacterial species, manganese also serves as a metal cofactor for proteins involved in central carbon metabolism and for the detoxification of reactive oxygen species (ROS) (Kehres and Maguire, 2003). Zinc-dependent enzymes that can detoxify ROS have also been identified (Battistoni, 2003). Furthermore, zinc was found to be associated with up to $5 \%$ of all bacterial proteins, of which more than $80 \%$ are enzymes (Andreini et al., 2006). In line with their essential role in many bacterial functions, acquisition of zinc and manganese has subsequently been shown to contribute to bacterial pathogenesis (reviewed in Kehl-Fie and Skaar, 2010).

Similar to siderophore and heme transport across the cytoplasmic membrane, ABC-type transporters are involved in bacterial uptake of zinc $\left(\mathrm{Zn}^{2+}\right)$ and manganese $\left(\mathrm{Mn}^{2+}\right)$ ions (Claverys, 2001). These transporter systems are composed of a cation binding protein that shuttles its substrate to its cognate transporter, a cytoplasmic ATP-binding protein that facilitates active transport, and the transmembrane protein that mediates transport through the cytoplasmic membrane. In Gram-negative bacteria, the cation binding protein is soluble and localized to the periplasm, while in Gram-positive bacteria it is a lipoprotein anchored to the extracellular membrane (Gilson et al., 1988; Tam and Saier, 1993; Sutcliffe and Russell, 1995). High-affinity ABC-type zinc transporters include ZnuABC of Gram-negative bacteria (Patzer and Hantke, 1998; Hantke, 2005), and AdcBCA of the Grampositive streptococci (Dintilhac et al., 1997; Panina et al., 2003). ABC-type manganese transporters have also been identified in several Gram-positive and Gram-negative bacteria (Claverys, 2001; Papp-Wallace and Maguire, 2006). In S. Typhimurium, for example, the ABC-type transporter SitABCD is found within a pathogenicity island and is not present in the closely related organism E. coli, indicating this transporter could have been acquired by horizontal gene transfer (Zhou et al., 1999). Of note, studies have shown some manganese transporters to facilitate the uptake of other divalent cations such as $\mathrm{Zn}^{2+}, \mathrm{Cd}^{2+}$, and $\mathrm{Fe}^{2+}$ at lower affinities, with a $K_{d}$ in the $\mu \mathrm{M}$ range (Kolenbrander et al., 1998; Kehres et al., 2002).

In addition to ABC-type transporters, bacteria also express homologs of the eukaryotic NRAMP transporter family (Kehres et al., 2000; Makui et al., 2000; Que and Helmann, 2000; Horsburgh et al., 2002). One example is the MntH protein of Salmonella and Escherichia, a membrane-bound, proton-coupled symporter with high specificity for manganese (Kehres et al., 2000); similar to the ABC-type manganese transporters, MntH can also transport other divalent cations at higher concentrations (Papp-Wallace and Maguire, 2006). Another discrete transporter of zinc and manganese uptake is ZupT, a permease with broad cation specificity belonging to the ZIP protein family (Grass et al., 2005; Karlinsey et al., 2010). Though metal uptake via ZupT is less specific than via the high-affinity ABC-type or NRAMP transporters, studies in $E$. coli have demonstrated this transporter to prefer zinc over manganese, copper, and iron (Grass et al., 2002, 2005; Taudte and Grass, 2010).

In addition to the role of these metals in essential cellular functions, evidence is mounting that specialized mechanisms of zinc and manganese acquisition contribute to bacterial pathogenesis; for instance, zinc and manganese are important cofactors in neutralizing reactive oxygen and nitrogen species, suggesting an important role for these metals in resisting these types of host antimicrobial responses (Lynch and Kuramitsu, 2000; Bowman et al., 2011). Supporting this, mutant strains of the pathogens Brucella abortus, Pasteurella multocida, and S. Typhimurium that 
lack the ZnuABC transporter are attenuated in systemic models of disease in mice (Campoy et al., 2002; Garrido et al., 2003; Kim et al., 2004; Ammendola et al., 2007). Furthermore, the expression of zinc transporters promotes Campylobacter jejuni, S. Typhimurium, and Acinetobacter baumannii colonization of mucosal tissues (Davis et al., 2009; Hood et al., 2012; Liu et al., 2012). For manganese acquisition, both the ABC-type transporters and the bacterial NRAMP homologs are known to contribute to systemic S. aureus and S. Typhimurium infection (Karlinsey et al., 2010; Kehl-Fie et al., 2013). Taken together, these studies indicate an important role for zinc and manganese sequestration by the host in controlling microbial infections with different pathogens.

\section{HOST MECHANISMS OF SEQUESTERING ZINC AND MANGANESE}

Compared to iron, less is known about the mechanisms the host employs to limit microbial access to metal micronutrients like zinc and manganese. Nevertheless, multiple strategies to limit the availability of these nutrients to pathogens have been identified in the mammalian host.

As described in the section on host iron sequestration, NRAMP1 is a proton-dependent exporter of $\mathrm{Fe}^{2+}$ and $\mathrm{Mn}^{2+}$ across the phagosomal membrane of vertebrates that confers resistance to various intracellular pathogens (Cellier et al., 2007). Another host protein known to sequester metal ions is the antimicrobial protein calprotectin (Corbin et al., 2008), a heterodimer of the two EF-hand calcium-binding proteins S100A8 and S100A9 (Teigelkamp et al., 1991), which exerts antimicrobial activity against several bacterial and fungal organisms by sequestering zinc and manganese (Corbin et al., 2008; Urban et al., 2009; Hood et al., 2012; Liu et al., 2012). Upon dimerizing, S100A8 and S100A9 form two metal binding sites, both of which can bind strongly to $\mathrm{Zn}^{2+}$, though one is also capable of binding manganese (Kehl-Fie et al., 2011; Damo et al., 2013). Like lactoferrin and lipocalin-2, calprotectin is expressed by neutrophils, where it constitutes approximately $50 \%$ of their cytosolic content (Hessian et al., 1993). Calprotectin is thought to be secreted by apoptotic neutrophils, where it is associated with their extracellular traps, also called NETs (Urban et al., 2009). Similar to lipocalin-2, the two subunits of calprotectin, S100A8 and S100A9, are also induced by IL-17 and IL-22 in mucosal epithelial cells (Zheng et al., 2008; Liu et al., 2012; Zindl et al., 2013).

To successfully colonize the host, pathogens have evolved mechanisms to resist the effects of calprotectin-dependent zinc and manganese sequestration. Manganese is most notably important as a cofactor for enzymes that detoxify ROS (Aguirre and Culotta, 2012). Consistent with this role, manganese binding by neutrophil-derived calprotectin inhibits the growth of S. aureus in tissue abscesses and increases the susceptibility of this pathogen to oxidative stress (Kehl-Fie et al., 2011). To counteract this, the specialized manganese transporters $\mathrm{MntABC}$ and $\mathrm{MntH}$ contribute to systemic $S$. aureus infection by competing with calprotectin for manganese (Kehl-Fie et al., 2013). In S. Typhimurium, expression of the high-affinity zinc transporter ZnuABC aids the pathogen in overcoming calprotectin-mediated zinc sequestration and promotes the growth of S. Typhimurium in the inflamed gut as well as Salmonella competition with the microbiota (Liu et al., 2012). Genes encoding a similar ABC-type zinc transporter are present in A. baumannii, where they also mediate resistance to zinc sequestration by calprotectin and serve to increase pathogenesis (Hood et al., 2012).

S100A12 (calgranulin C) is another calgranulin protein like S100A8 (calgranulin A) and S100A9 (calgranulin B) which binds to zinc and other divalent cations. Similar to S100A8 and S100A9, S100A12 is also predominantly expressed by neutrophils, monocytes and activated macrophages (Robinson and Hogg, 2000). However, unlike S100A8 and S100A9, S100A12 is not found in rodents and its role in metal sequestration is not well-defined. S100A12 seems to be mainly pro-inflammatory through the activation of mast cells but may also play a role in chemotaxis (Hsu et al., 2009; Perera et al., 2010). S100A12 has antiparasitic activity against filarial nematodes (Gottsch et al., 1999), although this activity does not appear to be dependent on metal sequestration. Calcitermin, a 15-residue C-terminal cleavage fragment of S100A12, can be found in the human airways and exhibit antimicrobial activity against E. coli, Pseudomonas aeruginosa, and C. albicans, both at low $\mathrm{pH}$ and in media with zinc (Cole et al., 2001).

Another S100 protein with antimicrobial and immunomodulatory activity is S100A7, which is largely expressed in the skin and other epithelia. This protein, also known as psoriasin, was originally discovered as an abundant protein in psoriatic keratinocytes (Gläser et al., 2005). Psoriasin is secreted by keratinocytes and has antimicrobial activity against $E$. coli, possibly by sequestering zinc (Gläser et al., 2005). The molecule is considered an important effector molecule of the cutaneous barrier and, like S100A8 and S100A9, is also induced by IL-17 and IL-22 (Liang et al., 2006).

\section{HOST vS. PATHOGENS: THE BATTLE FOR METALS AT THE INTERSECTION OF HEALTH AND DISEASE IN THE MUCOSA}

Sequestration of metal ions is one of the most important host strategies to limit the growth of bacterial and fungal pathogens. Metal limitation in the host is further enhanced during infection by the secretion of antimicrobial proteins that sequester metal ions, such as lipocalin-2 and calprotectin. Lipocalin-2 appears to be most effective in limiting the growth of commensal bacteria, as a number of pathogens have evolved or acquired additional siderophores to evade this response. In contrast, calprotectin restricts the growth of a variety of bacterial and fungal pathogens, including S. aureus, C. albicans, B. burgdorferi, A. baumannii, and Aspergillus nidulans (Lusitani et al., 2003; Urban et al., 2009; Moore et al., 2013). While both antimicrobial proteins are constitutively expressed by neutrophils, their expression-as well as the expression of other S100 proteins-may be induced in epithelial cells by pro-inflammatory stimuli like the Th17 cytokines IL-22 and IL-17 (Boniface et al., 2005; Zheng et al., 2008; Kerkhoff et al., 2012; Lee et al., 2012; Liu et al., 2012; Bando et al., 2013; Zindl et al., 2013).

Altogether, the secretion of antimicrobial proteins and the production of reactive oxygen and nitrogen species at the site of infection can reduce the growth of many microorganisms. Susceptibility of commensal bacteria to ROS may be exacerbated as a result of lipocalin-2 and calprotectin expression because these proteins sequester metals that serve as cofactors 
in bacterial enzymes responsible for neutralizing free radical species. However, in the harsh environment these responses create, microbes with metal scavenging ability can often survive and replicate, sometimes even dominating when commensal competition is reduced. This is the case for S. Typhimurium, which overcomes both lipocalin-2- and calprotectin-mediated metal sequestration to colonize the inflamed gut and compete with the microbiota (Raffatellu et al., 2009; Liu et al., 2012), a theme that likely applies to other pathogens (Figure 1). Therefore, the secretion of antimicrobial proteins like lipocalin-2 and calprotectin may have a detrimental effect on the host by killing commensal bacteria that are more susceptible to oxidative damage, neutrophil enzymatic activity, and metal nutrient deprivation.
Elevated lipocalin-2 and calprotectin levels observed in patients with inflammatory bowel disease (Cayatte et al., 2012; Østvik et al., 2013; Wang et al., 2013) may also be detrimental to the host because antimicrobial activity toward commensal bacteria likely contributes to the microbial imbalance observed in the digestive tract of these patients, known as dysbiosis (Salzman and Bevins, 2008; Manichanh et al., 2012). Sustained intestinal dysbiosis can lead to the overgrowth of potentially harmful bacteria termed pathobionts (Stecher et al., 2013).

The fact that transition metals are essential for proper development and function of the host further complicates the host metal economy during infection. For example, zinc is needed for immune development and function, but it also has to be

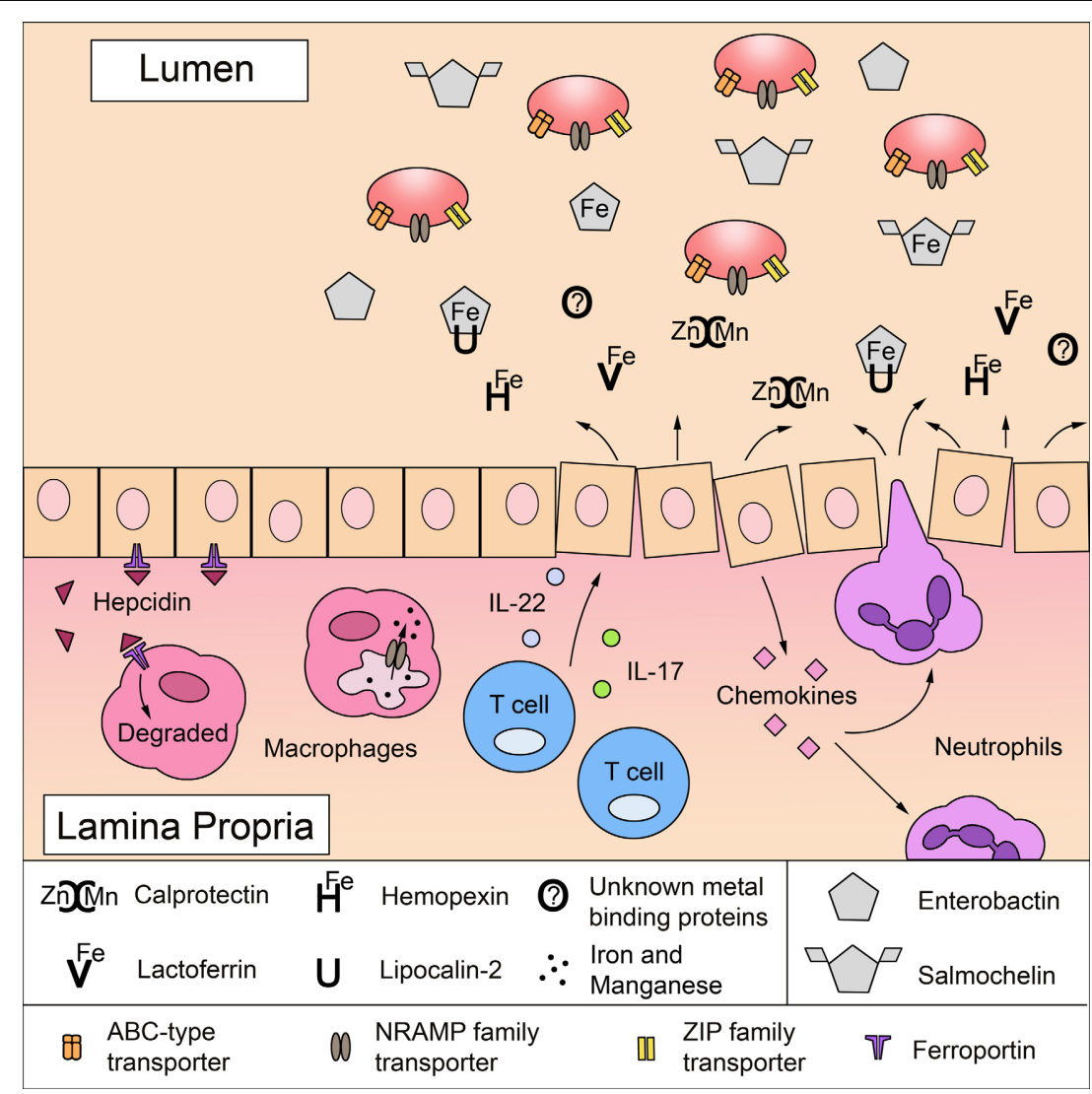

FIGURE 1 | A battle for metals in the intestinal mucosa: mechanisms of host metal sequestration and microbial metal acquisition. To limit microbial growth, the mammalian host sequesters free iron, zinc, and manganese ions by expressing proteins in the mucosa that directly bind metals or metal-binding agents in a process termed nutritional immunity. Lactoferrin binds to iron $(\mathrm{Fe})$ and calprotectin binds to zinc $(\mathrm{Zn})$ and manganese $(\mathrm{Mn})$. Hemopexin can limit the amount of circulating iron-bound heme $(\mathrm{He})$ and lipocalin-2 sequesters the bacterial iron-scavenging siderophore enterobactin. Upon infection, inflammatory mediators increase the expression of metal-sequestering proteins, which is detrimental to microbes lacking mechanisms to survive metal deprivation. Inflammatory cytokines, IL-17 and IL-22, produced by T cells induce epithelial cells to express antimicrobial proteins including lipocalin-2 and calprotectin. Furthermore, activated epithelial cells secrete CXC chemokines that recruit neutrophils to the site of infection; neutrophils also express high levels of lactoferrin, lipocalin-2, and calprotectin. Microbial infection and inflammation can stimulate the production of hepcidin in the liver and in macrophages, which further reduces iron availability by inducing the degradation of the cellular iron exporter ferroportin 1. In addition, the divalent metal ion transporter NRAMP1 can export manganese and iron out of the macrophage phagosome to further restrict metal availability to intracellular pathogens. To overcome metal starvation, pathogens (red ovals) employ several strategies to acquire iron, zinc and manganese. Highly specialized ABC-type transporters facilitate the uptake of zinc and manganese as well as iron bound to heme and siderophores. Siderophores, such as enterobactin, are iron-scavenging agents. Although lipocalin-2 can sequester enterobactin to limit microbial access to iron, some pathogens use salmochelin, a C-glucosylated derivative of enterobactin that cannot be bound by lipocalin-2. Some pathogens also express NRAMP family transporters and ZIP family transporters for the uptake of manganese and zinc. 
sequestered from staphylococcal abscesses in order to zinc-starve S. aureus during infection (Kehl-Fie et al., 2013). Furthermore, the amounts of metals vary in different organs (Kehl-Fie et al., 2013), which may be a basis for site-specific differences in the host's metal sequestration strategies. A contributing factor in these differences may include microbial colonization. In the healthy gut, and possibly at other mucosal sites colonized by commensal bacteria, host interactions with the microbiota likely regulate the low-level expression of metal binding proteins as well as the concentration of transition metals. At these mucosal sites and in other tissues and organs, it is plausible that other antimicrobial proteins besides lipocalin-2 and calprotectin may sequester metal ions but have yet to be identified.

In concert with other host defense strategies, nutritional immune responses at the mucosa can lead to beneficial outcomes for the host by reducing the colonization of invading pathogens. However, they can also alter the normal microbial flora, which may enhance the colonization of pathogens like S.Typhimurium or result in dysbiosis. Thus, it is important to take into account that metal sequestration strategies can be beneficial to the host, but may also potentially benefit pathogens or pathobionts that evade these responses. Moreover, investigating the mechanisms of host-microbe competition for metal ions may pave the way for developing novel therapeutics that are in critical need given the mounting global threat of antibiotic-resistant pathogens and pathobionts.

\section{ACKNOWLEDGMENTS}

We would like to thank Sean-Paul Nuccio for critical reading of the manuscript and Janet Z. Liu for contributing the artwork for our figure. Work in MR lab is supported by Public Health Service Grants AI083663 and by the Pacific Southwest Regional Center of Excellence for Biodefense and Emerging Infectious Disease Research funds (supported by award number U54AI065359 from the National Institute of Allergy and Infectious Diseases).

\section{REFERENCES}

Aguirre, J. D., and Culotta, V. C. (2012). Battles with iron: manganese in oxidative stress protection. J. Biol. Chem. 287, 13541-13548. doi: 10.1074/jbc.R111.312181

Aisen, P., Enns, C., and Wessling-Resnick, M. (2001). Chemistry and biology of eukaryotic iron metabolism. Int. J. Biochem. Cell Biol. 33, 940-959. doi: 10.1016/S1357-2725(01)00063-2

Aisen, P., Leibman, A., and Zweier, J. (1978). Stoichiometric and site characteristics of the binding of iron to human transferrin. J. Biol. Chem. 253, 1930-1937.

Ammendola, S., Pasquali, P., Pistoia, C., Petrucci, P., Petrarca, P., Rotilio, G., et al. (2007). High-affinity $\mathrm{Zn}^{2+}$ uptake system $\mathrm{ZnuABC}$ is required for bacterial zinc homeostasis in intracellular environments and contributes to the virulence of Salmonella enterica. Infect. Immun. 75, 5867-5876. doi: 10.1128/IAI. 00559-07

Andoh, A., Zhang, Z., Inatomi, O., Fujino, S., Deguchi, Y., Araki, Y., et al. (2005). Interleukin-22, a member of the IL-10 subfamily, induces inflammatory responses in colonic subepithelial myofibroblasts. Gastroenterology 129, 969-984. doi: 10.1053/j.gastro.2005.06.071

Andreini, C., Banci, L., Bertini, I., and Rosato, A. (2006). Zinc through the three domains of life. J. Proteome Res. 5, 3173-3178. doi: 10.1021/pr0603699

Andreini, C., Bertini, I., Cavallaro, G., Holliday, G. L., and Thornton, J. M. (2008). Metal ions in biological catalysis: from enzyme databases to general principles. J. Biol. Inorg. Chem. 13, 1205-1218. doi: 10.1007/s00775-008-0404-5

Andrews, N. C. (2000). Iron homeostasis: insights from genetics and animal models. Nat. Rev. Genet. 1, 208-217. doi: 10.1038/35042073
Andrews, S. C., Robinson, A. K., and Rodríguez Quiñones, F. (2003). Bacterial iron homeostasis. FEMS Microbiol. Rev. 27, 215-237. doi: 10.1016/S01686445(03)00055-X

Armitage, A. E., Eddowes, L. A., Gileadi, U., Cole, S., Spottiswoode, N., Selvakumar, T. A., et al. (2011). Hepcidin regulation by innate immune and infectious stimuli. Blood 118, 4129-4139. doi: 10.1182/blood-2011-04-351957

Aujla, S. J., Chan, Y. R., Zheng, M., Fei, M., Askew, D. J., Pociask, D. A., et al. (2008). IL-22 mediates mucosal host defense against Gram-negative bacterial pneumonia. Nat. Med. 14, 275-281. doi: 10.1038/nm1710

Awane, M., Andres, P. G., Li, D. J., and Reinecker, H. C. (1999). NF-kappa B-inducing kinase is a common mediator of IL-17-, TNF-alpha-, and IL-1 betainduced chemokine promoter activation in intestinal epithelial cells. J. Immunol. 162, 5337-5344.

Bachman, M. A., Miller, V. L., and Weiser, J. N. (2009). Mucosal lipocalin 2 has pro-inflammatory and iron-sequestering effects in response to bacterial enterobactin. PLoS Pathog. 5:e1000622. doi: 10.1371/journal.ppat.10 00622

Bachman, M. A., Oyler, J. E., Burns, S. H., Caza, M., Lépine, F., Dozois, C. M., et al. (2011). Klebsiella pneumoniae yersiniabactin promotes respiratory tract infection through evasion of lipocalin 2. Infect. Immun. 79, 3309-3316. doi: 10.1128/IAI.05114-11

Bando, M., Zou, X., Hiroshima, Y., Kataoka, M., Ross, K. F., Shinohara, Y., et al. (2013). Mechanism of interleukin-1 $\alpha$ transcriptional regulation of S100A9 in a human epidermal keratinocyte cell line. Biochim. Biophys. Acta 1829, 954-962. doi: 10.1016/j.bbagrm.2013.03.010

Battistoni, A. (2003). Role of prokaryotic $\mathrm{Cu}, \mathrm{Zn}$ superoxide dismutase in pathogenesis. Biochem. Soc. Trans. 31, 1326-1329. doi: 10.1042/BST0311326

Berger, T., Togawa, A., Duncan, G. S., Elia, A. J., You-Ten, A., Wakeham, A., et al. (2006). Lipocalin 2-deficient mice exhibit increased sensitivity to Escherichia coli infection but not to ischemia-reperfusion injury. Proc. Natl. Acad. Sci. U.S.A. 103, 1834-1839. doi: 10.1073/pnas.0510847103

Biemans-Oldehinkel, E., Doeven, M. K., and Poolman, B. (2006). ABC transporter architecture and regulatory roles of accessory domains. FEBS Lett. 580, 1023-1035. doi: 10.1016/j.febslet.2005.11.079

Birgegård, G., and Caro, J. (2009). Increased ferritin synthesis and iron uptake in inflammatory mouse macrophages. Scand. J. Haematol. 33, 43-48. doi: 10.1111/j.1600-0609.1984.tb02208.x

Boniface, K., Lecron, J.-C., Bernard, F.-X., Dagregorio, G., Guillet, G., Nau, F., et al. (2005). Keratinocytes as targets for interleukin-10-related cytokines: a putative role in the pathogenesis of psoriasis. Eur. Cytokine Netw. 16, 309-319.

Bowman, L. A. H., McLean, S., Poole R.K., and Fukuto, J. M. (2011). "The diversity of microbial responses to nitric oxide and agents of nitrosative stress: close cousins but not identical twins," in Advances in Microbial Physiology 59, ed R. K. Poole (London: Academic Press), 135-219.

Braun, V. (2009). FhuA (TonA), the career of a protein. J. Bacteriol. 191, 3431-3436. doi: 10.1128/JB.00106-09

Braun, V., and Braun, M. (2002). Active transport of iron and siderophore antibiotics. Curr. Opin. Microbiol. 5, 194-201. doi: 10.1016/S1369-5274(02)00298-9

Braun, V., and Hantke, K. (2011). Recent insights into iron import by bacteria. Curr. Opin. Chem. Biol. 15, 328-334. doi: 10.1016/j.cbpa.2011.01.005

Campoy, S., Jara, M., Busquets, N., Pérez De Rozas, A. M., Badiola, I., and Barbé, J. (2002). Role of the high-affinity zinc uptake $z n u A B C$ system in Salmonella enterica serovar typhimurium virulence. Infect. Immun. 70, 4721-4725. doi: 10.1128/IAI.70.8.4721-4725.2002

Carrano, C. J., and Raymond, K. N. (1979). Ferric ion sequestering agents. 2. Kinetics and mechanism of iron removal from transferrin by enterobactin and synthetic tricatechols. J. Am. Chem. Soc. 101, 5401-5404. doi: 10.1021/ja00512a047

Cayatte, C., Joyce-Shaikh, B., Vega, F., Boniface, K., Grein, J., Murphy, E., et al. (2012). Biomarkers of therapeutic response in the IL-23 pathway in inflammatory bowel disease. Clin. Transl. Gastroenterol. 3, e10. doi: 10.1038/ctg.2012.2

Cellier, M. F., Courville, P., and Campion, C. (2007). Nramp1 phagocyte intracellular metal withdrawal defense. Microbes Infect. 9, 1662-1670. doi: 10.1016/j.micinf.2007.09.006

Chakraborty, R., Storey, E., and Van Der Helm, D. (2007). Molecular mechanism of ferricsiderophore passage through the outer membrane receptor proteins of Escherichia coli. Biometals 20, 263-274. doi: 10.1007/s10534-006-9060-9

Claverys, J. P. (2001). A new family of high-affinity ABC manganese and zinc permeases. Res. Microbiol. 152, 231-243. doi: 10.1016/S0923-2508(01)01195-0 
Cole, A. M., Kim, Y. H., Tahk, S., Hong, T., Weis, P., Waring, A. J., et al. (2001). Calcitermin, a novel antimicrobial peptide isolated from human airway secretions. FEBS Lett. 504, 5-10. doi: 10.1016/S0014-5793(01)02731-4

Corbin, B. D., Seeley, E. H., Raab, A., Feldmann, J., Miller, M. R., Torres, V. J., et al. (2008). Metal chelation and inhibition of bacterial growth in tissue abscesses. Science 319, 962-965. doi: 10.1126/science.1152449

Correnti, C., and Strong, R. K. (2012). Mammalian siderophores, siderophorebinding lipocalins, and the labile iron pool. J. Biol. Chem. 287, 13524-13531. doi: 10.1074/jbc.R111.311829

Crosa, J. H., and Walsh, C. T. (2002). Genetics and assembly line enzymology of siderophore biosynthesis in bacteria. Microbiol. Mol. Biol. Rev. 66, 223-249. doi: 10.1128/MMBR.66.2.223-249.2002

Crouch, M.-L. V., Castor, M., Karlinsey, J. E., Kalhorn, T., and Fang, F. C. (2008). Biosynthesis and IroC-dependent export of the siderophore salmochelin are essential for virulence of Salmonella enterica serovar Typhimurium. Mol. Microbiol. 67, 971-983. doi: 10.1111/j.1365-2958.2007.06089.x

Damo, S. M., Kehl-Fie, T. E., Sugitani, N., Holt, M. E., Rathi, S., Murphy, W. J., et al. (2013). Molecular basis for manganese sequestration by calprotectin and roles in the innate immune response to invading bacterial pathogens. Proc. Natl. Acad. Sci. U.S.A. 110 3841-3846. doi: 10.1073/pnas.1220341110

Davis, L. M., Kakuda, T., and Dirita, V. J. (2009). A Campylobacter jejuni znuA orthologue is essential for growth in low-zinc environments and chick colonization. J. Bacteriol. 191, 1631-1640. doi: 10.1128/JB.01394-08

Deriu, E., Liu, J. Z., Pezeshki, M., Edwards, R. A., Ochoa, R. J., Contreras, H., et al. (2013). Probiotic bacteria reduce Salmonella Typhimurium intestinal colonization by competing for iron. Cell Host Microbe 14, 26-37. doi: 10.1016/j.chom.2013.06.007

Dintilhac, A., Alloing, G., Granadel, C., and Claverys, J.-P. (1997). Competence and virulence of Streptococcus pneumoniae: Adc and PsaA mutants exhibit a requirement for $\mathrm{Zn}$ and $\mathrm{Mn}$ resulting from inactivation of putative ABC metal permeases. Mol. Microbiol. 25, 727-739. doi: 10.1046/j.1365-2958.1997.5111879.x

Drakesmith, H., and Prentice, A. M. (2012). Hepcidin and the iron-infection axis. Science 338, 768-772. doi: 10.1126/science.1224577

Fischbach, M. A., Lin, H., Liu, D. R., and Walsh, C. T. (2006). How pathogenic bacteria evade mammalian sabotage in the battle for iron. Nat. Chem. Biol. 2, 132-138. doi: 10.1038/nchembio771

Flo, T. H., Smith, K. D., Sato, S., Rodriguez, D. J., Holmes, M. A., Strong, R. K., et al. (2004). Lipocalin 2 mediates an innate immune response to bacterial infection by sequestrating iron. Nature 432, 917-921. doi: 10.1038/nature03104

Forbes, J. R. (2003). Iron, manganese, and cobalt transport by Nramp1 (Slc1la1) and Nramp2 (Slc1la2) expressed at the plasma membrane. Blood 102, 1884-1892. doi: 10.1182/blood-2003-02-0425

Forbes, J. R., and Gros, P. (2001). Divalent-metal transport by NRAMP proteins at the interface of host-pathogen interactions. Trends Microbiol. 9, 397-403. doi: 10.1016/S0966-842X(01)02098-4

Fritsche, G., Dlaska, M., Barton, H., Theurl, I., Garimorth, K., and Weiss, G. (2003). Nrampl functionality increases inducible nitric oxide synthase transcription via stimulation of IFN regulatory factor 1 expression. J. Immunol. 171, 1994-1998.

Fritsche, G., Nairz, M., Libby, S. J., Fang, F. C., and Weiss, G. (2012). Slc11a1 (Nramp1) impairs growth of Salmonella enterica serovar typhimurium in macrophages via stimulation of lipocalin-2 expression. J. Leukoc. Biol. 92, 353-359. doi: 10.1189/jlb.1111554

Fritsche, G., Nariz, M., Werner, E. R., Barton, H. C., and Weiss, G. (2008). Nramp1functionality increases iNOS expression via repression of IL-10 formation. Eur. J. Immonol. 38, 3060-3067. doi: 10.1002/eji.200838449

Garrido, M. E., Bosch, M., Medina, R., Llagostera, M., Pérez De Rozas, A. M., Badiola, I., et al. (2003). The high-affinity zinc-uptake system znuACB is under control of the iron-uptake regulator (fur) gene in the animal pathogen Pasteurella multocida. FEMS Microbiol. Lett. 221, 31-37. doi: 10.1016/S03781097(03)00131-9

Gilson, E., Alloing, G., Schmidt, T., Claverys, J. P., Dudler, R., and Hofnung, M. (1988). Evidence for high affinity binding-protein dependent transport systems in gram-positive bacteria and in Mycoplasma. EMBO J. 7, 3971-3974.

Gläser, R., Harder, J., Lange, H., Bartels, J., Christophers, E., and Schröder, J.-M. (2005). Antimicrobial psoriasin (S100A7) protects human skin from Escherichia coli infection. Nat. Immunol. 6, 57-64. doi: 10.1038/ni1142

Goetz, D. H., Holmes, M. A., Borregaard, N., Bluhm, M. E., Raymond, K. N., and Strong, R. K. (2002). The neutrophil lipocalin NGAL is a bacteriostatic agent that interferes with siderophore-mediated iron acquisition. Mol. Cell 10, 1033-1043. doi: 10.1016/S1097-2765(02)00708-6

Gottsch, J. D., Eisinger, S. W., Liu, S. H., and Scott, A. L. (1999). Calgranulin C has filariacidal and filariastatic activity. Infect. Immun. 67, 6631-6636.

Grass, G., Franke, S., Taudte, N., Nies, D. H., Kucharski, L. M., Maguire, M. E., et al. (2005). The metal permease ZupT from Escherichia coli is a transporter with a broad substrate spectrum. J. Bacteriol. 187, 1604-1611. doi: 10.1128/JB.187.5.1604-1611.2005

Grass, G., Wong, M. D., Rosen, B. P., Smith, R. L., and Rensing, C. (2002). ZupT is a $\mathrm{Zn}$ (II) uptake system in Escherichia coli. J. Bacteriol. 184, 864-866. doi: 10.1128/JB.184.3.864-866.2002

Griffiths, E. (1999). "Iron in biological systems," in Iron and Infection: Molecular, Physiological and Clinical Aspects, eds J. J. Bullen and E. Griffiths (Chichester: Wiley-Interscience), 1-25.

Haas, H. (2003). Molecular genetics of fungal siderophore biosynthesis and uptake: the role of siderophores in iron uptake and storage. Appl. Microbiol. Biotechnol. 62, 316-330. doi: 10.1007/s00253-003-1335-2

Hantke, K. (2005). Bacterial zinc uptake and regulators. Curr. Opin. Microbiol. 8, 196-202. doi: 10.1016/j.mib.2005.02.001

Hantke, K., Nicholson, G., Rabsch, W., and Winkelmann, G. (2003). Salmochelins, siderophores of Salmonella enterica and uropathogenic Escherichia coli strains, are recognized by the outer membrane receptor IroN. Proc. Natl. Acad. Sci. U.S.A. 100, 3677-3682. doi: 10.1073/pnas.0737682100

Hessian, P. A., Edgeworth, J., and Hogg, N. (1993). MRP-8 and MRP-14, two abundant $\mathrm{Ca}^{2+}$-binding proteins of neutrophils and monocytes. J. Leukoc. Biol. 53, 197-204.

Heymann, P., Gerads, M., Schaller, M., Dromer, F., Winkelmann, G., and Ernst, J. F. (2002). The siderophore iron transporter of Candida albicans (Sitlp/Arnlp) mediates uptake of ferrichrome-type siderophores and is required for epithelial invasion. Infect. Immun. 70, 5246-5255. doi: 10.1128/IAI.70.9.5246-5255.2002

Hood, M. I., Mortensen, B. L., Moore, J. L., Zhang, Y., Kehl-Fie, T. E., Sugitani, N., et al. (2012). Identification of an Acinetobacter baumannii zinc acquisition system that facilitates resistance to calprotectin-mediated zinc sequestration. PLoS Pathog. 8:e1003068. doi: 10.1371/journal.ppat.1003068

Horsburgh, M. J., Wharton, S. J., Cox, A. G., Ingham, E., Peacock, S., and Foster, S. J. (2002). MntR modulates expression of the PerR regulon and superoxide resistance in Staphylococcus aureus through control of manganese uptake. Mol. Microbiol. 44, 1269-1286. doi: 10.1046/j.1365-2958.2002.02944.x

Hsu, K., Champaiboon, C., Guenther, B. D., Sorenson, B. S., Khammanivong, A., Ross, K. F., et al. (2009). Anti-infective protective properties of S100 calgranulins. Antiinflamm. Antiallergy. Agents Med. Chem. 8, 290-305. doi: $10.2174 / 187152309789838975$

Jabado, N., Jankowski, A., Dougaparsad, S., Picard, V., Grinstein, S., and Gros, P. (2000). Natural resistance to intracellular infections: natural resistanceassociated macrophage protein 1 (Nrampl) functions as a $\mathrm{pH}$-dependent manganese transporter at the phagosomal membrane. J. Exp. Med. 192, 1237-1248. doi: 10.1084/jem.192.9.1237

Kao, C.-Y., Huang, F., Chen, Y., Thai, P., Wachi, S., Kim, C., et al. (2005). Up-regulation of CC chemokine ligand 20 expression in human airway epithelium by IL-17 through a JAK-independent but MEK/NF-kappaB-dependent signaling pathway. J. Immunol. 175, 6676-6685.

Karlinsey, J. E., Maguire, M. E., Becker, L. A., Crouch, M.-L. V., and Fang, F. C. (2010). The phage shock protein PspA facilitates divalent metal transport and is required for virulence of Salmonella enterica sv. Typhimurium. Mol. Microbiol. 78, 669-685. doi: 10.1111/j.1365-2958.2010.07357.x

Keen, C. L., Ensunsa, J. L., and Clegg, M. S. (2000). Manganese metabolism in animals and humans including the toxicity of manganese. Met. Ions Biol. Syst. 37, 89-121.

Kehl-Fie, T. E., Chitayat, S., Hood, M. I., Damo, S., Restrepo, N., Garcia, C., et al. (2011). Nutrient metal sequestration by calprotectin inhibits bacterial superoxide defense, enhancing neutrophil killing of Staphylococcus aureus. Cell Host Microbe 10, 158-164. doi: 10.1016/j.chom.2011.07.004

Kehl-Fie, T. E., and Skaar, E. P. (2010). Nutritional immunity beyond iron: a role for manganese and zinc. Curr. Opin. Chem. Biol. 14, 218-224. doi: 10.1016/j.cbpa.2009.11.008

Kehl-Fie, T. E., Zhang, Y., Moore, J. L., Farrand, A. J., Hood, M. I., Rathi, S., et al. (2013). MntABC and MntH contribute to systemic Staphylococcus aureus infection by competing with calprotectin for nutrient manganese. Infect. Immun. 81, 3395-3405. doi: 10.1128/IAI.00420-13 
Kehres, D. G., Janakiraman, A., Slauch, J. M., and Maguire, M. E. (2002). SitABCD is the alkaline $\mathrm{Mn}^{2+}$ transporter of Salmonella enterica serovar Typhimurium. J. Bacteriol. 184, 3159-3166. doi: 10.1128/JB.184.12.3159-3166.2002

Kehres, D. G., and Maguire, M. E. (2003). Emerging themes in manganese transport, biochemistry and pathogenesis in bacteria. FEMS Microbiol. Rev. 27, 263-290. doi: 10.1016/S0168-6445(03)00052-4

Kehres, D. G., Zaharik, M. L., Finlay, B. B., and Maguire, M. E. (2000). The NRAMP proteins of Salmonella typhimurium and Escherichia coli are selective manganese transporters involved in the response to reactive oxygen. Mol. Microbiol. 36, 1085-1100. doi: 10.1046/j.1365-2958.2000.01922.x

Kerkhoff, C., Voss, A., Scholzen, T. E., Averill, M. M., Zänker, K. S., and Bornfeldt, K. E. (2012). Novel insights into the role of S100A8/A9 in skin biology. Exp. Dermatol. 21, 822-826. doi: 10.1111/j.1600-0625.2012.01571.x

Kim, S., Watanabe, K., Shirahata, T., and Watarai, M. (2004). Zinc uptake system (znuA locus) of Brucella abortus is essential for intracellular survival and virulence in mice. J. Vet. Med. Sci. 66, 1059-1063. doi: 10.1292/jvms.66.1059

King, J. C. (2011). Zinc: an essential but elusive nutrient. Am. J. Clin. Nutr. 94, 679S-684S. doi: 10.3945/ajcn.110.005744

Kolenbrander, P. E., Andersen, R. N., Baker, R. A., and Jenkinson, H. F. (1998). The adhesion-associated sca operon in Streptococcus gordonii encodes an inducible high-affinity ABC transporter for $\mathrm{Mn}^{2+}$ uptake. J. Bacteriol. 180, 290-295.

Krause, A., Neitz, S., Mägert, H. J., Schulz, A., Forssmann, W. G., Schulz-Knappe, P., et al. (2000). LEAP-1, a novel highly disulfide-bonded human peptide, exhibits antimicrobial activity. FEBS Lett. 480, 147-150. doi: 10.1016/S00145793(00)01920-7

Krewulak, K. D., and Vogel, H. J. (2008). Structural biology of bacterial iron uptake. Biochim. Biophys. Acta 1778, 1781-1804. doi: 10.1016/j.bbamem.2007.07.026

Lawlor, K. M., and Payne, S. M. (1984). Aerobactin genes in Shigella spp. J. Bacteriol. 160, 266-272.

Lee, M. J., Lee, J.-K., Choi, J. W., Lee, C.-S., Sim, J. H., Cho, C.-H., et al. (2012). Interleukin-6 induces S100A9 expression in colonic epithelial cells through STAT3 activation in experimental ulcerative colitis. PLOS ONE 7:e38801. doi: 10.1371/journal.pone.0038801

Liang, S. C., Tan, X.-Y., Luxenberg, D. P., Karim, R., Dunussi-Joannopoulos, K., Collins, M., et al. (2006). Interleukin (IL)-22 and IL-17 are coexpressed by Th17 cells and cooperatively enhance expression of antimicrobial peptides. J. Exp. Med. 203, 2271-2279. doi: 10.1084/jem.20061308

Lieu, P. T., Heiskala, M., Peterson, P. A., and Yang, Y. (2001). The roles of iron in health and disease. Mol. Aspects Med. 22, 1-87. doi: 10.1016/S00982997(00)00006-6

Liu, J. Z., Jellbauer, S., Poe, A. J., Ton, V., Pesciaroli, M., Kehl-Fie, T. E., et al. (2012). Zinc sequestration by the neutrophil protein calprotectin enhances Salmonella growth in the inflamed gut. Cell Host Microbe 11, 227-239. doi: 10.1016/j.chom.2012.01.017

Luo, M., Fadeev, E. A., and Groves, J. T. (2005). Mycobactin-mediated iron acquisition within macrophages. Nat. Chem. Biol. 1, 149-153. doi: 10.1038/nchembio717

Lusitani, D., Malawista, S. E., and Montgomery, R. R. (2003). Calprotectin, an abundant cytosolic protein from human polymorphonuclear leukocytes, inhibits the growth of Borrelia burgdorferi. Infect. Immun. 71, 4711-4716. doi: 10.1128/IAI.71.8.4711-4716.2003

Lynch, M., and Kuramitsu, H. (2000). Expression and role of superoxide dismutases (SOD) in pathogenic bacteria. Microbes Infect. 2, 1245-1255. doi: 10.1016/S1286-4579(00)01278-8

Makui, H., Roig, E., Cole, S. T., Helmann, J. D., Gros, P., and Cellier, M. F. (2000). Identification of the Escherichia coli K-12 Nramp orthologue (MntH) as a selective divalent metal ion transporter. Mol. Microbiol. 35, 1065-1078. doi: 10.1046/j.1365-2958.2000.01774.x

Manichanh, C., Borruel, N., Casellas, F., and Guarner, F. (2012). The gut microbiota in IBD. Nat. Rev. Gastroenterol. Hepatol. 9, 599-608. doi: 10.1038/nrgastro.2012.152

Masson, P. L., Heremans, J. F., and Schonne, E. (1969). Lactoferrin, an ironbinding protein in neutrophilic leukocytes. J. Exp. Med. 130, 643-658. doi: 10.1084/jem.130.3.643

McAllister, F., Henry, A., Kreindler, J. L., Dubin, P. J., Ulrich, L., Steele, C., et al. (2005). Role of IL-17A, IL-17F, and the IL-17 receptor in regulating growthrelated oncogene-alpha and granulocyte colony-stimulating factor in bronchial epithelium: implications for airway inflammation in cystic fibrosis. J. Immunol. $175,404-412$.
Miethke, M., and Marahiel, M. A. (2007). Siderophore-based iron acquisition and pathogen control. Microbiol. Mol. Biol. Rev. 71, 413-451. doi: 10.1128/MMBR.00012-07

Moeck, G. S., and Coulton, J. W. (2002). TonB-dependent iron acquisition: mechanisms of siderophore-mediated active transport. Mol. Microbiol. 28, 675-681. doi: 10.1046/j.1365-2958.1998.00817.x

Moore, J. L., Becker, K. W., Nicklay, J. J., Boyd, K. L., Skaar, E. P., and Caprioli, R. M. (2013). Imaging mass spectrometry for assessing temporal proteomics: analysis of calprotectin in Acinetobacter baumannii pulmonary infection. Proteomics. doi: 10.1002/pmic.201300046. [Epub ahead of print].

Morgan, J. J. (2000). Manganese in natural waters and earth's crust: its availability to organisms. Met. Ions Biol. Syst. 37, 1-34.

Neilands, J. B. (1995). Siderophores: structure and function of microbial iron transport compounds. J. Biol. Chem. 270, 26723-26726.

Nemeth, E., Rivera, S., Gabayan, V., Keller, C., Taudorf, S., Pedersen, B. K., et al. (2004a). IL-6 mediates hypoferremia of inflammation by inducing the synthesis of the iron regulatory hormone hepcidin. J. Clin. Invest. 113, 1271-1276. doi: 10.1172/JCI20945

Nemeth, E., Tuttle, M. S., Powelson, J., Vaughn, M. B., Donovan, A., Ward, D. M., et al. (2004b). Hepcidin regulates cellular iron efflux by binding to ferroportin and inducing its internalization. Science 306, 2090-2093. doi: 10.1126/science. 1104742

Nemeth, E., Valore, E. V., Territo, M., Schiller, G., Lichtenstein, A., and Ganz, T. (2003). Hepcidin, a putative mediator of anemia of inflammation, is a type II acute-phase protein. Blood 101, 2461-2463. doi: 10.1182/blood-2002-10-3235

Nicolas, G. (2002). Severe iron deficiency anemia in transgenic mice expressing liver hepcidin. Proc. Natl. Acad. Sci. U.S.A. 99, 4596-4601. doi: 10.1073/pnas.072632499

Nicolas, G., Bennoun, M., Devaux, I., Beaumont, C., Grandchamp, B., Kahn, A., et al. (2001). Lack of hepcidin gene expression and severe tissue iron overload in upstream stimulatory factor 2 (USF2) knockout mice. Proc. Natl. Acad. Sci. U.S.A. 98, 8780-8785. doi: 10.1073/pnas.151179498

Nobles, C. L., and Maresso, A. W. (2011). The theft of host heme by Gram-positive pathogenic bacteria. Metallomics 3, 788-796. doi: 10.1039/c1mt00047k

O'Brien, I. G., and Gibson, F. (1970). The structure of enterochelin and related 2,3dihydroxy-N-benzoylserine conjugates from Escherichia coli. Biochim. Biophys. Acta 215, 393-402. doi: 10.1016/0304-4165(70)90038-3

Østvik, A. E., Granlund, A. V. B., Torp, S. H., Flatberg, A., Beisvåg, V., Waldum, H. L., et al. (2013). Expression of Toll-like receptor-3 is enhanced in active inflammatory bowel disease and mediates the excessive release of lipocalin 2. Clin. Exp. Immunol. 173, 502-511. doi: 10.1111/cei.12136

Panina, E. M., Mironov, A. A., and Gelfand, M. S. (2003). Comparative genomics of bacterial zinc regulons: enhanced ion transport, pathogenesis, and rearrangement of ribosomal proteins. Proc. Natl. Acad. Sci. U.S.A. 100, 9912-9917. doi: 10.1073/pnas. 1733691100

Papp-Wallace, K. M., and Maguire, M. E. (2006). Manganese transport and the role of manganese in virulence. Annu. Rev. Microbiol. 60, 187-209. doi: 10.1146/annurev.micro.60.080805.142149

Park, C. H., Valore, E. V., Waring, A. J., and Ganz, T. (2001). Hepcidin, a urinary antimicrobial peptide synthesized in the liver. J. Biol. Chem. 276, 7806-7810. doi: 10.1074/jbc.M008922200

Patzer, S. I., and Hantke, K. (1998). The ZnuABC high-affinity zinc uptake system and its regulator Zur in Escherichia coli. Mol. Microbiol. 28, 1199-1210. doi: 10.1046/j.1365-2958.1998.00883.x

Perera, C., Mcneil, H. P., and Geczy, C. L. (2010). S100 Calgranulins in inflammatory arthritis. Immunol. Cell Biol. 88, 41-49. doi: 10.1038/icb.2009.88

Perry, R. D., and San Clemente, C. L. (1979). Siderophore synthesis in Klebsiella pneumoniae and Shigella sonnei during iron deficiency. J. Bacteriol. 140, 1129-1132.

Peyssonnaux, C., Zinkernagel, A. S., Datta, V., Lauth, X., Johnson, R. S., and Nizet, V. (2006). TLR4-dependent hepcidin expression by myeloid cells in response to bacterial pathogens. Blood 107, 3727-3732. doi: 10.1182/blood-2005-06-2259

Philpott, C. C. (2006). Iron uptake in fungi: a system for every source. Biochim. Biophys. Acta 1763, 636-645. doi: 10.1016/j.bbamcr.2006.05.008

Pollack, J. R., and Neilands, J. B. (1970). Enterobactin, an iron transport compound from Salmonella typhimurium. Biochem. Biophys. Res. Commun. 38, 989-992. doi: 10.1016/0006-291X(70)90819-3

Posey, J. E., and Gherardini, F. C. (2000). Lack of a role for iron in the Lyme disease pathogen. Science 288, 1651-1653. doi: 10.1126/science.288.5471.1651 
Postle, K., and Kadner, R. J. (2003). Touch and go: tying TonB to transport. Mol. Microbiol. 49, 869-882. doi: 10.1046/j.1365-2958.2003. 03629.x

Que, Q., and Helmann, J. D. (2000). Manganese homeostasis in Bacillus subtilis is regulated by $\mathrm{MntR}$, a bifunctional regulator related to the diphtheria toxin repressor family of proteins. Mol. Microbiol. 35, 1454-1468. doi: 10.1046/j.13652958.2000.01811.x

Raffatellu, M., George, M. D., Akiyama, Y., Hornsby, M. J., Nuccio, S.-P., Paixao, T. A., et al. (2009). Lipocalin-2 resistance confers an advantage to Salmonella enterica serotype Typhimurium for growth and survival in the inflamed intestine. Cell Host Microbe 5, 476-486. doi: 10.1016/j.chom.2009.03.011

Ramanan, N., and Wang, Y. (2000). A high-affinity iron permease essential for Candida albicans virulence. Science 288, 1062-1064. doi: 10.1126/science.288.5468.1062

Raymond, K. N., Müller, G. and Matzanke, B. F. (2005). Complexation of iron by siderophres. A review of their solution and structural chemistry and biological funcion. Top. Curr. Chem. 123, 49-102. doi: 10.1007/3-540-13 099-3_2

Robinson, M. J., and Hogg, N. (2000). A Comparison of Human S100A12 with MRP-14 (S100A9). Biochem. Biophys. Res. Commun. 275, 865-870. doi: 10.1006/bbrc. 2000.3407

Rodriguez, R., Jung, C., Gabayan, V., Deng, J. C., Ganz, T., Nemeth, E., et al. (2013). Hepcidin induction by pathogens and pathogen-derived molecules is strongly dependent on interlukin-6. Infect. Immun. doi: 10.1128/IAI.00983-13. [Epub ahead of print].

Rogers, H. J., Synge, C., Kimber, B., and Bayley, P. M. (1977). Production of enterochelin by Escherichia coli 0111. Biochim. Biophys. Acta 497, 548-557. doi: 10.1016/0304-4165(77)90211-2

Ross, S. L., Tran, L., Winters, A., Lee, K.-J., Plewa, C., Foltz, I., et al. (2012). Molecular mechanism of hepcidin-mediated ferroportin internalization requires ferroportin lysines, not tyrosines or JAK-STAT. Cell Metab. 15, 905-917. doi: 10.1016/j.cmet.2012.03.017

Salzman, N. H., and Bevins, C. L. (2008). Negative interactions with the microbiota: IBD. Adv. Exp. Med. Biol. 635, 67-78. doi: 10.1007/978-0-387-09550-9_6

Soe-Lin, S., Apte, S. S., Andriopoulos, B., Andrews, M. C., Schranzhofer, M., Kahawita, T., et al. (2009). Nrampl promotes efficient macrophage recycling of iron following erythrophagocytosis in vivo. Proc. Natl. Acad. Sci. U.S.A. 106, 5960-5965. doi: 10.1073/pnas.0900808106

Srinivasan, G., Aitken, J. D., Zhang, B., Carvalho, F. A., Chassaing, B., Shashidharamurthy, R., et al. (2012). Lipocalin 2 deficiency dysregulates iron homeostasis and exacerbates endotoxin-induced sepsis. J. Immunol. 189, 1911-1919. doi: 10.4049/jimmunol.1200892

Stecher, B., Maier, L., and Hardt, W.-D. (2013). 'Blooming' in the gut: how dysbiosis might contribute to pathogen evolution. Nat. Rev. Microbiol. 11, 277-284. doi: 10.1038/nrmicro2989

Steinbakk, M., Naess-Andresen, C. F., Lingaas, E., Dale, I., Brandtzaeg, P., and Fagerhol, M. K. (1990). Antimicrobial actions of calcium binding leucocyte L1 protein, calprotectin. Lancet 336, 763-765. doi: 10.1016/0140-6736(90)93237-J

Sutcliffe, I. C., and Russell, R. R. (1995). Lipoproteins of gram-positive bacteria. J. Bacteriol. 177, 1123-1128.
Tam, R., and Saier, M. H. (1993). Structural, functional, and evolutionary relationships among extracellular solute-binding receptors of bacteria. Microbiol. Rev. 57, 320-346.

Tapiero, H., and Tew, K. D. (2003). Trace elements in human physiology and pathology: zinc and metallothioneins. Biomed. Pharmacother. 57, 399-411. doi: 10.1016/S0753-3322(03)00081-7

Taudte, N., and Grass, G. (2010). Point mutations change specificity and kinetics of metal uptake by ZupT from Escherichia coli. Biometals 23, 643-656. doi: 10.1007/s10534-010-9319-z

Teigelkamp, S., Bhardwaj, R. S., Roth, J., Meinardus-Hager, G., Karas, M., and Sorg, C. (1991). Calcium-dependent complex assembly of the myeloic differentiation proteins MRP-8 and MRP-14. J. Biol. Chem. 266, 13462-13467.

Urban, C. F., Ermert, D., Schmid, M., Abu-Abed, U., Goosmann, C., Nacken, W., et al. (2009). Neutrophil extracellular traps contain calprotectin, a cytosolic protein complex involved in host defense against Candida albicans. PLoS Pathog. 5:e1000639. doi: 10.1371/journal.ppat.1000639

Waldron, K. J., Rutherford, J. C., Ford, D., and Robinson, N. J. (2009). Metalloproteins and metal sensing. Nature 460, 823-830. doi: 10.1038/nature08300

Wang, S., Wang, Z., Shi, H., Heng, L., Juan, W., Yuan, B., et al. (2013). Faecal calprotectin concentrations in gastrointestinal diseases. J. Int. Med. Res. 41, 1357-1361. doi: 10.1177/0300060513488499

Zheng, Y., Valdez, P. A., Danilenko, D. M., Hu, Y., Sa, S. M., Gong, Q., et al. (2008). Interleukin-22 mediates early host defense against attaching and effacing bacterial pathogens. Nat. Med. 14, 282-289. doi: 10.1038/nm1720

Zhou, D., Hardt, W. D., and Galán, J. E., (1999). Salmonella typhimurium encodes a putative iron transport system within the centisome 63 pathogenicity island. Infect. Immun. 67, 1974-1981.

Zindl, C. L., Lai, J.-F., Lee, Y. K., Maynard, C. L., Harbour, S. N., Ouyang, W., et al. (2013). IL-22-producing neutrophils contribute to antimicrobial defense and restitution of colonic epithelial integrity during colitis. Proc. Natl. Acad. Sci. U.S.A. 110, 12768-12773. doi: 10.1073/pnas.1300318110

Conflict of Interest Statement: The authors declare that the research was conducted in the absence of any commercial or financial relationships that could be construed as a potential conflict of interest.

Received: 15 October 2013; paper pending published: 05 November 2013; accepted: 04 January 2014; published online: 24 January 2014.

Citation: Diaz-Ochoa VE, Jellbauer S, Klaus S and Raffatellu M (2014) Transition metal ions at the crossroads of mucosal immunity and microbial pathogenesis. Front. Cell. Infect. Microbiol. 4:2. doi: 10.3389/fcimb.2014.00002

This article was submitted to the journal Frontiers in Cellular and Infection Microbiology.

Copyright (C) 2014 Diaz-Ochoa, Jellbauer, Klaus and Raffatellu. This is an openaccess article distributed under the terms of the Creative Commons Attribution License (CC BY). The use, distribution or reproduction in other forums is permitted, provided the original author(s) or licensor are credited and that the original publication in this journal is cited, in accordance with accepted academic practice. No use, distribution or reproduction is permitted which does not comply with these terms. 